\title{
CRESCIMENTO DE PLANTAS JOVENS DE LIMEIRA ÁCIDA 'TAHITI' SOB LÂMINAS DE IRRIGAÇÃO'
}

\section{JOSÉ ALVES JÚNIOR ${ }^{2}$, CLÁUDIO R. DA SILVA ${ }^{2}$, RAFAEL V. RIBEIRO ${ }^{3}$, TONNY J. A. DA SILVA ${ }^{3}$, MARCOS V. FOLEGATTI ${ }^{4}$}

\begin{abstract}
RESUMO: Este estudo avaliou o efeito de lâminas de irrigação no crescimento vegetativo de limeira ácida 'Tahiti' (Citrus latifolia Tan) sob condições de campo. Os tratamentos consistiram de irrigações por gotejamento baseadas em 100\% (T3) e 50\% (T2) da evapotranspiração da cultura medida em lisímetro de pesagem e o tratamento sem irrigação (T1). O delineamento experimental foi inteiramente casualizado, com dez repetições. Mediram-se o diâmetro do caule e a altura das plantas mensalmente, ao passo que a área foliar, o volume e a projeção de copa foram determinados após 14 meses do início dos tratamentos. Medidas de assimilação de $\mathrm{CO}_{2}$, condutância estomática e potencial da água na folha foram realizadas para verificar o estado fisiológico das plantas em virtude dos tratamentos. Plantas irrigadas submetidas ao T3 apresentaram os maiores valores de área foliar, diâmetro de caule, altura de planta e projeção de copa. Valores intermediários dessas variáveis foram observados em T2, quando comparado ao T3 e ao T1. O menor desenvolvimento das plantas não irrigadas (T1) foi possivelmente causado pelos menores valores de condutância estomática e assimilação de $\mathrm{CO}_{2}$.
\end{abstract}

PALAVRAS-CHAVE: Citrus latifolia Tan., manejo da irrigação, estresse hídrico.

\section{GROWTH OF YOUNG 'TAHITI' ACID LIME TREES UNDER IRRIGATION LEVELS}

ABSTRACT: This study evaluated the effect of irrigation levels growth of young 'Tahiti' acid lime (Citrus latifolia Tan.) trees under field conditions. Treatments consisted of drip irrigation based on $100 \%$ (T3) and 50\% (T2) of crop evapotranspiration measured by a weight lysimeter as well as nonirrigated plants (T1). The experiment was carried out in a completely randomized design with 10 replications. The trunk diameter and plant height were measured monthly, whereas the leaf area, the volume and the top of the tree projection were determined 14 months after setting treatments. Measurements of $\mathrm{CO}_{2}$ assimilation, stomatal conductance and plant water potential were taken to verify the plant physiological status under the applied treatments. Irrigated plants submitted to T3 showed higher leaf area, trunk diameter, plant height and volume of tree projection. Intermediate values of these variables were observed in T2, compared to T3 and T1. The development of nonirrigated plants was probably impaired by low values of stomatal conductance and $\mathrm{CO}_{2}$ assimilation.

KEYWORDS: Citrus latifolia Tan., irrigation management, water stress.

\footnotetext{
${ }^{1}$ Estudo financiado pela Fundação de Amparo à Pesquisa do Estado de São Paulo - FAPESP - Processo: 03/08509-8.

${ }^{2}$ Eng $^{\mathbf{0}}$ Agrônomo, Doutorando, Departamento de Engenharia Rural, ESALQ/USP, Piracicaba - SP, Fone: (0XX19) 3429.4217 - R:266, jalves@esalq.usp.br

${ }^{3}$ Eng $^{\mathrm{o}}$ Agrônomo, Pesquisador Científico, Centro de Pesquisa e Desenvolvimento de Ecofisiologia e Biofísica, Instituto Agronômico, Campinas - SP.

${ }^{4}$ Eng $^{\mathrm{o}}$ Agrônomo, Prof. Doutor, Departamento de Engenharia Rural, ESALQ/USP, Piracicaba - SP.

Recebido pelo Conselho Editorial em: 20-9-2004

Aprovado pelo Conselho Editorial em: 10-5-2005
} 


\section{INTRODUÇÃO}

No período de formação do pomar, o crescimento vegetativo é altamente afetado pela falta d'água, e alguns trabalhos indicam que, a longo prazo, os efeitos do déficit hídrico são mais danosos ao crescimento da planta do que ao crescimento dos frutos (LEVY et al., 1978). MARLER \& DAVIES (1990) compararam o crescimento de laranjeiras 'Hamilin' com um ano de idade, mantidas a 20; 45 e $65 \%$ de esgotamento da água no solo, e observaram decréscimo do crescimento radicular e de ramos das plantas mantidas a 65\%, enquanto os tratamentos com 20 e $45 \%$ não determinaram diferenças quanto ao crescimento vegetativo. DAVIES \& ZALMAN (2000), estudando o efeito da irrigação em laranjeiras 'Hamilin' jovens na Flórida, verificaram que não houve diferenças no crescimento vegetativo quando as plantas foram mantidas entre 30 e $50 \%$ de esgotamento da água do solo. CASTEL \& BUJ (1992) observaram redução do diâmetro do tronco e do índice de área foliar quando plantas de tangerineira 'Clementina' foram irrigadas com apenas $40 \%$ da evaporação do Tanque Classe A. Esses autores verificaram que o crescimento ótimo para os dois primeiros anos ocorreu com a aplicação semanal de 70\% da água evaporada do tanque. Em estudo parecido, CASTEL (1993), aplicando seis níveis de irrigação entre 30 e $200 \%$ da evaporação em plantas jovens de 'Clementina de Nules', sugeriu relação linear entre o aumento no diâmetro do tronco e o aumento na taxa de aplicação de água.

É comum a utilização de métodos de irrigação baseados na tensão da água no solo (tensiometria) e/ou nas condições meteorológicas (evapotranspiração) (PEREIRA et al., 2002). Entretanto, os limites críticos estabelecidos, normalmente, são obtidos por meio de experimentos de longa duração, comparando-se a produtividade ou dados de crescimento da planta em determinado nível de umidade, região e tipo de solo. DAVIES \& ALBRIGO (1994) comentam que a análise de variáveis fisiológicas, tais como condutância estomática, potencial da água na folha ou no fruto e assimilação de $\mathrm{CO}_{2}$, é fundamental para melhor compreensão dos fatores que limitam a produtividade e/ou crescimento das plantas.

Quando considerada a limeira ácida 'Tahiti', estudos sobre a influência do manejo da irrigação no crescimento de plantas em condição de campo são escassos. Nesse contexto, teve-se o objetivo de avaliar, em condições de campo, o crescimento vegetativo da limeira ácida 'Tahiti' (Citrus latifolia Tan.) em resposta a lâminas de irrigação, obtidas pelo fornecimento de 50 e $100 \%$ da necessidade hídrica da cultura, determinada com lisímetro de pesagem eletrônica.

\section{MATERIAL E MÉTODOS}

O experimento foi realizado na Fazenda Areão, Escola Superior de Agricultura "Luiz de

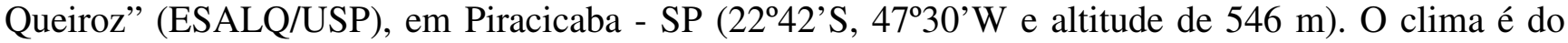
tipo Cwa pela classificação de Köeppen, denominado subtropical úmido e caracterizado por estiagem no inverno, com temperaturas médias mensais entre $18^{\circ} \mathrm{C}$ e $22^{\circ} \mathrm{C}$ no decorrer do ano. A temperatura média anual é de $21,4^{\circ} \mathrm{C}$, e o total anual de chuva é de $1.257 \mathrm{~mm}$ (SENTELHAS \& PEREIRA, 2000). O solo da área experimental foi classificado como Nitossolo Vermelho, segundo a classificação brasileira (EMBRAPA, 1999). A umidade volumétrica média na capacidade de campo (-10 $\mathrm{kPa}$ ) foi de $40 \%$ e no ponto de murcha permanente igual a $30 \%(-1.500 \mathrm{kPa})$, com densidade média de $1.300 \mathrm{~kg} \mathrm{~m}^{-3}$. Esses valores foram determinados por abertura de trincheiras em três pontos da área, com coleta de amostras indeformadas a cada $0,2 \mathrm{~m}$ até $1,0 \mathrm{~m}$ de profundidade, utilizando anéis volumétricos.

As limeiras ácidas 'Tahiti' [Citrus latifolia (Yu. Tanaka) Tanaka], enxertadas sobre plantas de citrumeleiro 'Swingle' [Poncirus trifoliata (L.) Raf. x C. paradisi Macf.], foram plantadas em espaçamento 7x4 m, obtendo-se o total de 322 plantas em área experimental de aproximadamente 1 ha. O plantio foi realizado em sulcos na primeira quinzena de junho de 2001, sendo a calagem e adubação 
realizadas de acordo com RAIJ et al. (1992). Os tratos culturais consistiram de pulverizações com inseticidas, roçagem e capinas manuais nas entrelinhas e linhas, respectivamente. $\mathrm{O}$ sistema de irrigação utilizado no pomar foi por gotejamento, sendo uma sublinha de irrigação na forma de anel para cada planta, contendo quatro emissores autocompensantes eqüidistantes entre si, com vazão de $4 \mathrm{~L} \mathrm{~h}^{-1}$, totalizando $16 \mathrm{~L} \mathrm{~h}^{-1}$ por planta.

Para a determinação do consumo hídrico da planta, foi utilizado lisímetro de pesagem eletrônica com dimensões de $2,7 \mathrm{~m}$ de diâmetro e $0,8 \mathrm{~m}$ de profundidade, cuja construção e calibragem está descrita por CAMPECHE (2002). A diferença de massa no lisímetro em dias consecutivos foi considerada equivalente ao consumo de água do sistema solo-planta, em litros por dia, sendo esse valor considerado nas irrigações. O monitoramento meteorológico da área, visando à estimativa da evapotranspiração de referência diária (ETo) pelo método de Penman-Monteith FAO-56, parametrizada por ALLEN et al. (1998), foi realizado por estação agrometeorológica automática, distante $70 \mathrm{~m}$ do lisímetro.

Em agosto de 2002 (pomar com 14 meses de idade), plantas que apresentavam em média altura de 1,60 m, diâmetro de caule igual a $3,0 \mathrm{~cm}$ e área foliar de $2,65 \mathrm{~m}^{2}$, foram submetidas aos seguintes tratamentos: sem irrigação (T1); 50\% (T2) e 100\% (T3) de reposição do volume de água evapotranspirado pela cultura $\left(\mathrm{ET}_{\mathrm{C}}\right)$, usando dois (T2) e quatro (T3) gotejadores por planta, adaptados com distribuidores de descarga proporcionando quatro pontos de molhamento.

Avaliações da altura da planta e diâmetro do caule a 0,05 m acima do ponto de enxertia foram realizadas mensalmente entre agosto de 2002 e setembro de 2003. Após 14 meses do início dos tratamentos, mediram-se a área foliar, o volume e a projeção da copa por meio de método indireto (WELLES \& COHEN, 1996), baseado em fotografias da silhueta das árvores aliado a medidas de um analisador de dossel (LAI-2000, LICOR, Lincoln, EUA). A partir de fotografias frontais das plantas, foram retiradas coordenadas $\mathrm{x}, \mathrm{y}$ do contorno da copa, utilizando um programa computacional gráfico (AutoCAD $^{\circledR}$, Autodesk, San Rafael, EUA). Para integrar os dados do LAI-2000 e as coordenadas x,y do contorno da copa, utilizou-se do programa computacional C2000 (LAI-2000 Support Software, LICOR, Lincoln, EUA). O programa fornece a densidade foliar $\left(\mathrm{m}^{2} \mathrm{~m}^{-3}\right)$, sendo a área foliar total da planta $\left(\mathrm{m}^{2}\right)$ obtida multiplicando-se a densidade foliar pelo volume da copa $\left(\mathrm{m}^{3}\right)$. Ao final de 14 meses, foi realizada a colheita, sendo essa a primeira realizada no pomar. Os frutos maduros foram coletados, identificados e posteriormente pesados.

Avaliou-se, também, em 24 de setembro de 2003, o potencial da água no xilema ( $\Psi$ w) às $6 \mathrm{~h}$ (hora local), pelo método da câmara de pressão (KAUFMANN, 1968), utilizando-se da câmara modelo 3005 (Soil Moisture Equipment Co., Santa Bárbara, EUA). O $\Psi_{\mathrm{W}}$ foi medido em um ramo por planta (repetição), contendo de 4 a 8 folhas, com aproximadamente três meses de idade, localizado no lado oeste da copa das plantas.

As medidas da assimilação de $\mathrm{CO}_{2}$ e condutância estomática foram realizadas sob radiação fotossinteticamente ativa de $250 \mu \mathrm{mol} \mathrm{m} \mathrm{m}^{-2} \mathrm{~s}^{-1}$ e condições naturais de temperatura e déficit de pressão de vapor do ar em 26 de setembro de 2003. Essas medidas foram realizadas em quatro plantas por tratamento, em folhas expostas à radiação solar, de tamanho e idade semelhantes, sendo amostradas às 9; 12 e 15 h com analisador de gases por infravermelho (LI-6400, LICOR, Lincoln, EUA). Durante as medidas, a concentração de $\mathrm{CO}_{2}$ do ar permaneceu entre 350 e $360 \mu \mathrm{mol} \mathrm{mol}^{-1}$.

O delineamento experimental adotado foi o inteiramente ao acaso, com três tratamentos e dez repetições, sendo cada repetição constituída por uma planta. Os resultados foram submetidos à análise de variância (ANOVA) e as médias comparadas pelo teste Tukey, a 5\% de probabilidade. Os tratamentos apresentaram bordadura formada por duas plantas adjacentes à parcela, na linha de plantio, assim como a primeira e última linha que margeiam o pomar. A freqüência e o tempo de irrigação foram os mesmos em todos os tratamentos, variando-se apenas a vazão dos emissores. 


\section{RESULTADOS E DISCUSSÃO}

Após 14 meses do início dos tratamentos, T1 e T2 ocasionaram menor desenvolvimento vegetativo (Tabela 1). A altura das plantas, diâmetro do caule, projeção da copa e área foliar foram maiores nas plantas irrigadas com $100 \%$ de $\operatorname{ET}_{C}(\mathrm{P}<0,05)$. Embora não significativo, o volume da copa apresentou incremento de $25 \%$ em T3, em relação a T1.

TABELA 1. Altura, diâmetro do caule, área foliar, volume e projeção da copa e produção de limeira ácida 'Tahiti' após 14 meses do início do experimento (setembro de 2003) em plantas não irrigadas e submetidas a 50 e 100\% de reposição da água evapotranspirada.

\begin{tabular}{lccc}
\hline \multirow{2}{*}{ Características } & \multicolumn{3}{c}{${\text { Irrigação* }\left(\% \text { de } \mathrm{ET}_{\mathrm{C}}\right)}$} \\
\cline { 2 - 4 } & 0 & 50 & 100 \\
\hline Altura $(\mathrm{m})$ & $2,36^{\mathrm{b}}$ & $2,48^{\mathrm{b}}$ & $2,75^{\mathrm{a}}$ \\
Diâmetro do caule $(\mathrm{cm})$ & $6,47^{\mathrm{b}}$ & $6,81^{\mathrm{ab}}$ & $7,29^{\mathrm{a}}$ \\
Volume da copa $\left(\mathrm{m}^{3}\right)$ & $6,86^{\mathrm{a}}$ & $8,13^{\mathrm{a}}$ & $9,13^{\mathrm{a}}$ \\
Projeção da copa $\left(\mathrm{m}^{2}\right)$ & $4,06^{\mathrm{b}}$ & $5,22^{\mathrm{a}}$ & $5,62^{\mathrm{a}}$ \\
Área foliar $\left(\mathrm{m}^{2}\right)$ & $12,19^{\mathrm{b}}$ & $18,05^{\mathrm{ab}}$ & $21,94^{\mathrm{a}}$ \\
Produção por planta $(\mathrm{kg})$ & $2,70^{\mathrm{a}}$ & $3,55^{\mathrm{a}}$ & $5,06^{\mathrm{a}}$ \\
Produção total $(\mathrm{kg})$ & 27,00 & 33,16 & 48,84 \\
\hline
\end{tabular}

* Médias seguidas por letras diferentes na linha apresentam diferença estatística, pelo teste Tukey, a 5\% de probabilidade.

Os valores representam a média de 10 repetições, com exceção dos valores de produção total.

As plantas submetidas aos tratamentos com suprimento de água apresentaram maiores valores das variáveis medidas, concordando com CASTEL (1993), que sugere relação linear entre o aumento no diâmetro do caule e o aumento na quantidade de água aplicada. As diferenças observadas foram, provavelmente, causadas pelo déficit hídrico (entre agosto e novembro de 2002, e entre março e setembro de 2003) ocorrido durante o período de estudo (Figura 1A).

Assim como o crescimento vegetativo, o reprodutivo apresentou-se superior em T3, no qual a produção por planta e total foram, respectivamente, cerca de 1,87 e 1,81 vez maior que em T1. Embora a produção por planta de T3 tenha sido praticamente o dobro de $\mathrm{T} 1$, as médias não diferiram significativamente devido à alta heterogeneidade de produção entre plantas do mesmo tratamento. Apesar da precocidade de produção, PASSOS et al. (1977), MARCONDES (1991) e GAYET et al. (1995) relatam que somente a partir do quinto ano de produção que se obtêm rendimentos econômicos, quando se espera homogeneidade de produção entre plantas.

Quando considerada a evolução do crescimento em diâmetro do caule e altura das plantas, notase a existência de períodos de maior incremento de ambas as variáveis (Figura 2). Entre outubro de 2002 e abril de 2003, a taxa de crescimento do diâmetro do caule foi mais acentuada, coincidindo com a época de maior disponibilidade hídrica e energética, considerando tanto os valores de radiação solar como os de temperatura do ar (Figura 1B). Da mesma forma, as taxas de crescimento da altura das plantas entre os meses de janeiro e março de 2003 aumentaram cerca de quatro vezes em relação à taxa de crescimento observada entre outubro e janeiro (Figura 2B).

Avaliando o período que se estende de novembro de 2002 a março de 2003, a precipitação acumulada atingiu valores de $1.058,3 \mathrm{~mm}$ e a radiação global média de $593,56 \mathrm{MJ} \mathrm{m}^{-2} \mathrm{mês}^{-1}$. Uma vez que a precipitação tenha atendido a demanda hídrica da atmosfera e da cultura, as plantas não foram submetidas à restrição hídrica e assim os tratamentos não apresentaram diferenças significativas, sendo registradas taxas semelhantes de crescimento de diâmetro de caule e altura das plantas (Figura 2).

Embora sem apresentar diferença estatística, T3 proporcionou maior altura de planta desde o terceiro mês de experimento, sendo cerca de $17 \%$ maior em relação às plantas submetidas a $\mathrm{T} 1$ ao 
término do período de avaliação (Figura 2B). Os resultados sugerem que a deficiência hídrica, que atingiu 281,1 mm em setembro de 2003 (Figura 1A), promoveu maiores diferenças quando consideradas as características vegetativas avaliadas. Tal fato pode ser verificado pelos maiores valores de taxa de crescimento do diâmetro do caule entre agosto e outubro de 2002 e junho a setembro de 2003, assim como maiores taxas de crescimento em altura no período de agosto a outubro de 2002 e abril a setembro de 2003.
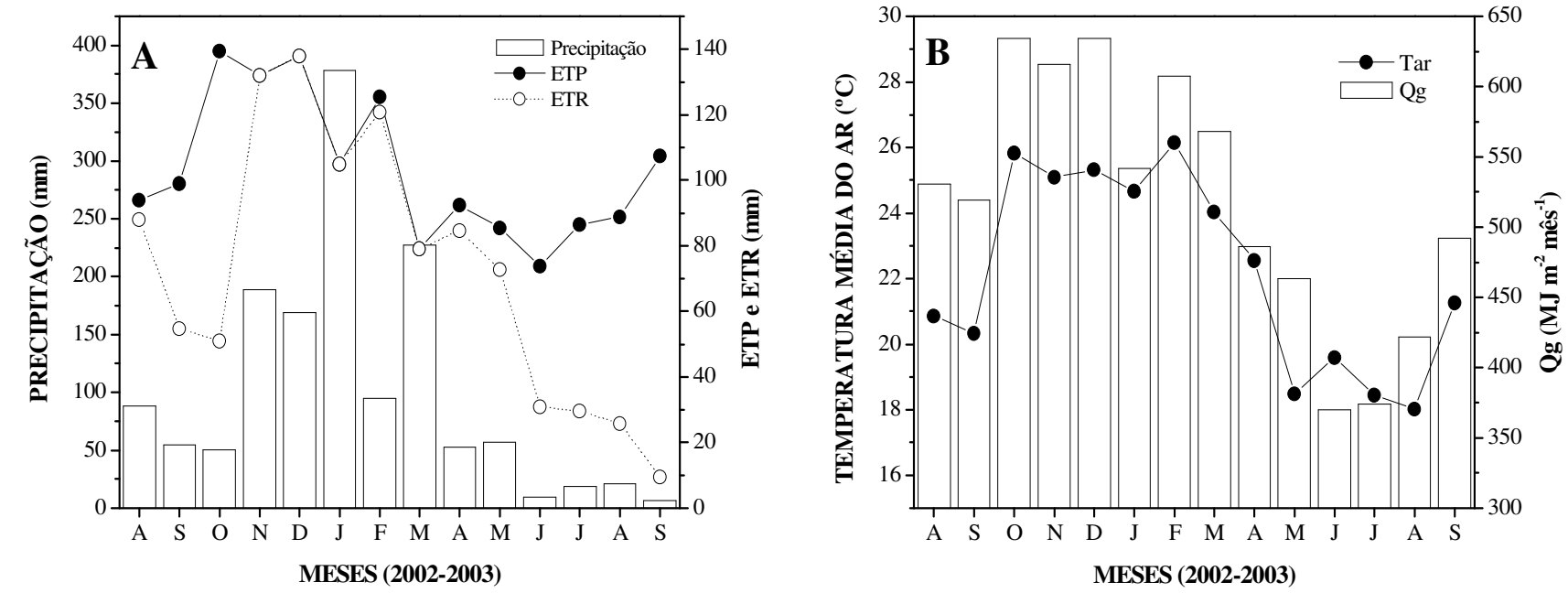

FIGURA 1. Precipitação, evapotranspiração de referência ou potencial (ETP) e real (ETR) (A), temperatura média do ar (Tar) e radiação global mensal $(\mathrm{Qg})(\mathrm{B})$ durante o período experimental (agosto de 2002 a setembro de 2003) em Piracicaba - SP.
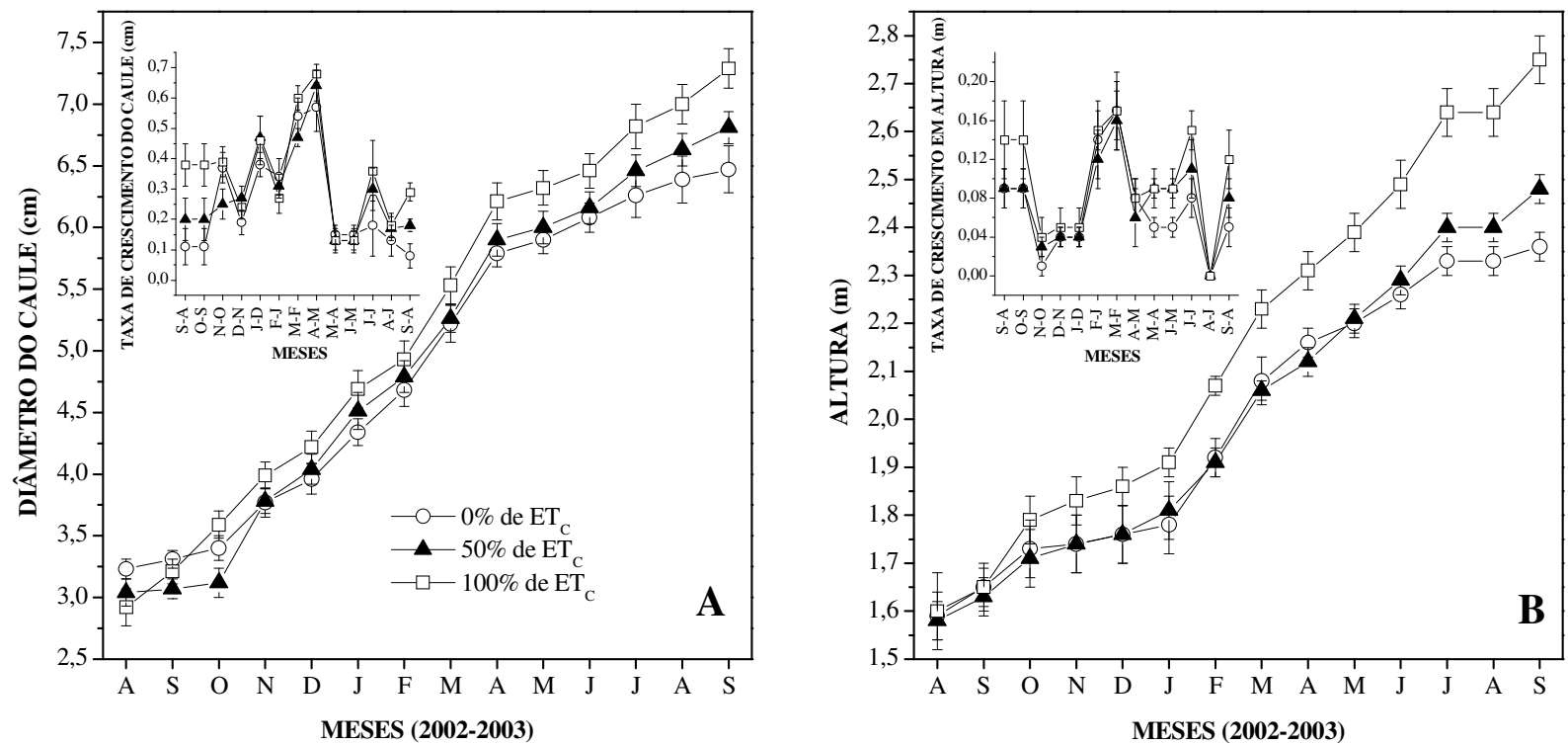

FIGURA 2. Crescimento mensal absoluto e relativo do diâmetro do caule (A) e altura (B) de limeira ácida 'Tahiti' submetida a 0; 50 e 100\% de reposição da água evapotranspirada pela cultura. Pontos representam o valor médio de dez repetições \pm erro-padrão da média.

A literatura relata (CASTEL \& BUJ, 1992; CASTEL, 1993) que o crescimento vegetativo é altamente afetado pela falta d'água no período de formação do pomar. Neste estudo, observou-se menor projeção de copa nas plantas do tratamento não irrigado em relação aos irrigados com 50 e $100 \%$ da $\mathrm{ET}_{\mathrm{C}}$, assim como maior desenvolvimento da área foliar no tratamento irrigado com $100 \%$ da ET $_{\text {C }}$ CASTEL \& BUJ (1992), em estudos com tangerineiras 'Clementina', observaram diferença na 
área foliar apenas a partir da redução da lâmina de irrigação para $40 \%$ da evaporação do Tanque Classe A. Esses autores verificaram que o crescimento ótimo para os dois primeiros anos ocorreu com a aplicação de $70 \%$ da água evaporada do Tanque Classe A. Verificou-se, portanto, que o desenvolvimento vegetativo foi dependente do regime de irrigação imposto à cultura, fato também relatado por SHALHEVET \& LEVY (1990). Na Espanha, CASTEL (1994) também verificou que irrigações baseadas em $50 \%$ da $\mathrm{ET}_{\mathrm{C}}$ provocaram estresse hídrico com redução do crescimento e produtividade em plantas jovens de 'Clementina', em relação à reposição de $100 \%$ da ET $_{\mathrm{C}}$.

A irrigação proporcionou maior assimilação de $\mathrm{CO}_{2}$, entretanto esse efeito variou dependendo do horário considerado (Figura 3). A assimilação de $\mathrm{CO}_{2}$ nas plantas submetidas aos tratamentos T2 e T3 manteve-se praticamente a mesma quando avaliada às 9 e 12 h (Figuras 3A e B). Essa tendência se alterou às $15 \mathrm{~h}$, horário de maior demanda atmosférica ( $\mathrm{DPV}_{\text {folha-ar }}$ de $2,18 \mathrm{kPa}$ e temperatura do ar ao redor de $30^{\circ} \mathrm{C}$ ), quando a assimilação de $\mathrm{CO}_{2}$ foi reduzida em $45 \%$ em T2 e $65 \%$ em T1 (Figura 3C). Sob deficiência hídrica, as plantas tendem a reduzir a perda excessiva de água pelo fechamento estomático o que pode determinar menor disponibilidade de substrato $\left(\mathrm{CO}_{2}\right)$ para a atividade fotossintética (MEDINA et al., 1998, MACHADO et al., 1999).

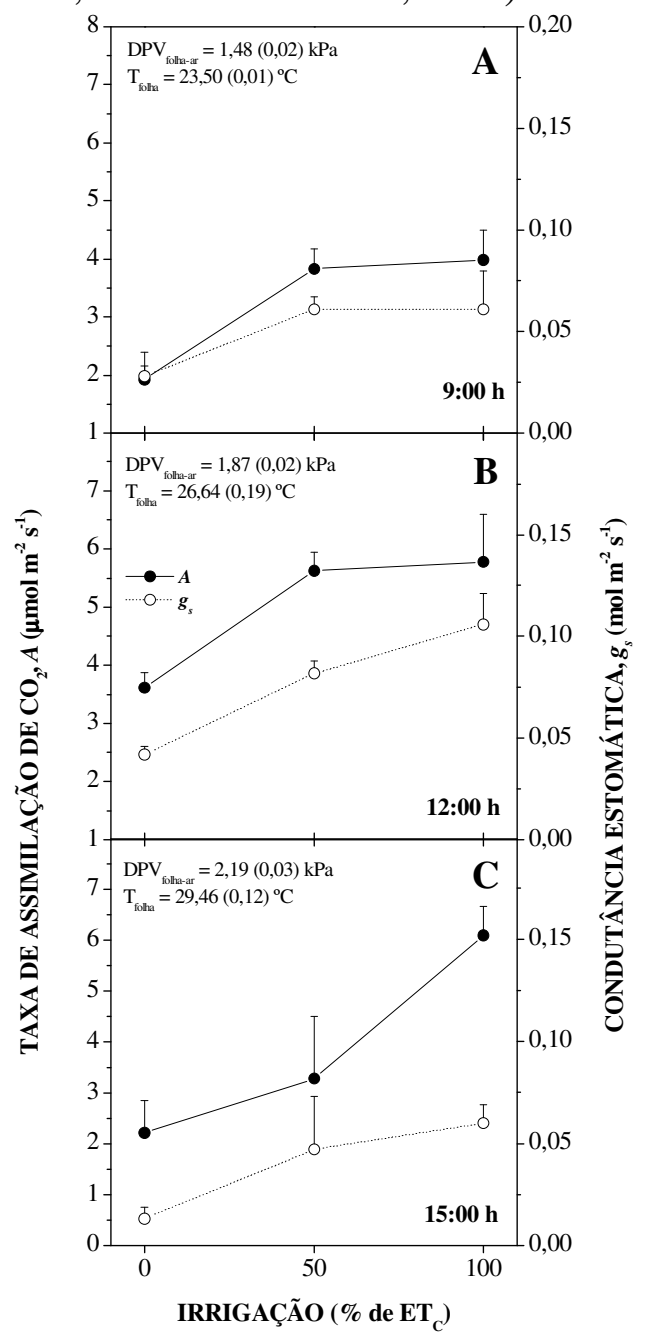

FIGURA 3. Taxa de assimilação de $\mathrm{CO}_{2}$ e condutância estomática em limeira ácida 'Tahiti' submetida a 0; 50 e 100\% de reposição da água evapotranspirada pela cultura, medidas às 9 (A), 12 (B) e $15 \mathrm{~h}(\mathrm{C})$. Pontos representam o valor médio de quatro repetições e as barras verticais o erro-padrão da média. Os valores médios (erro-padrão da média) da diferença de pressão de vapor folha-ar ( $\left.\mathrm{DPV}_{\text {folha-ar }}\right)$ e temperatura foliar $\left(\mathrm{T}_{\text {folha }}\right)$, considerando todos os tratamentos, são indicados em cada horário de medida. 
Pode-se notar que a condutância estomática e a assimilação de $\mathrm{CO}_{2}$ apresentaram a mesma tendência, decrescendo com a redução da disponibilidade hídrica, mostrando que a restrição de substrato fotossintético é um dos fatores que determinaram menor assimilação de $\mathrm{CO}_{2}$ nas plantas não irrigadas (T1). De fato, SYVERTSEN \& LLOYD (1994) afirmam que a redução da fotossíntese de plantas cítricas em condições de deficiência hídrica é causada primariamente pelo aumento na resistência estomática. A menor condutância estomática das plantas não irrigadas (T1) concorda com os menores valores de $\Psi_{\mathrm{W}}$ (Figura 4), atingindo $0,015 \mathrm{~mol} \mathrm{~m}^{-2} \mathrm{~s}^{-1}$ às $15 \mathrm{~h}$ (Figuras 3C). Os valores de $\Psi_{\mathrm{W}}$ observados condizem com a literatura (SYVERTSEN, 1982; MEDINA et al., 1998; MACHADO et al., 1999), especialmente quando considerado T2 e T3 (Figura 4). Entretanto, os valores de $\Psi_{\mathrm{W}} \mathrm{em}$ T1 são especialmente baixos (- 1,6 $\mathrm{MPa})$ para o horário de medida $(6 \mathrm{~h})$, quando a planta apresentaria o máximo de hidratação, evidenciando a intensidade de estresse hídrico a que as plantas desse tratamento estavam submetidas. MEDINA et al. (1998) observaram valores de $\Psi_{\mathrm{W}}$ inferiores a -2,0 MPa, às 6 h, em laranjeira 'Valência' após dez dias da suspensão da irrigação. Evidentemente, tal situação dependerá da demanda atmosférica do período, assim como do volume de solo explorado, podendo baixos valores de $\Psi_{\mathrm{W}}$ serem alcançados em maior ou menor tempo.

Embora medidas em dias distintos, as reduções da assimilação de $\mathrm{CO}_{2}$ e condutância estomática (26-9-2003) foram coerentes com as alterações do potencial da água no xilema (24-9-2003) (Figuras 3 e 4). No entanto, a diminuição da assimilação em T2 às $15 \mathrm{~h}$ não parece ter sido proporcionada apenas pela redução da condutância estomática, uma vez que se encontraram reduções de $22 \%$ e $46 \%$ para condutância estomática e assimilação de $\mathrm{CO}_{2}$, respectivamente. De acordo com NOBEL (1999), alterações da abertura estomática têm efeito proporcionalmente maior na transpiração se comparada com a assimilação de $\mathrm{CO}_{2}$, sendo a porcentagem de redução na assimilação de $\mathrm{CO}_{2}$ inferior à da condutância estomática. Desde que os resultados não evidenciaram tal fato, sugere-se que a falta de irrigação promoveu menor assimilação de $\mathrm{CO}_{2}$ devido a possíveis comprometimentos das reações bioquímicas da fotossíntese, como constatado por VU \& YELENOSKY (1988) em laranjeira 'Valência'.

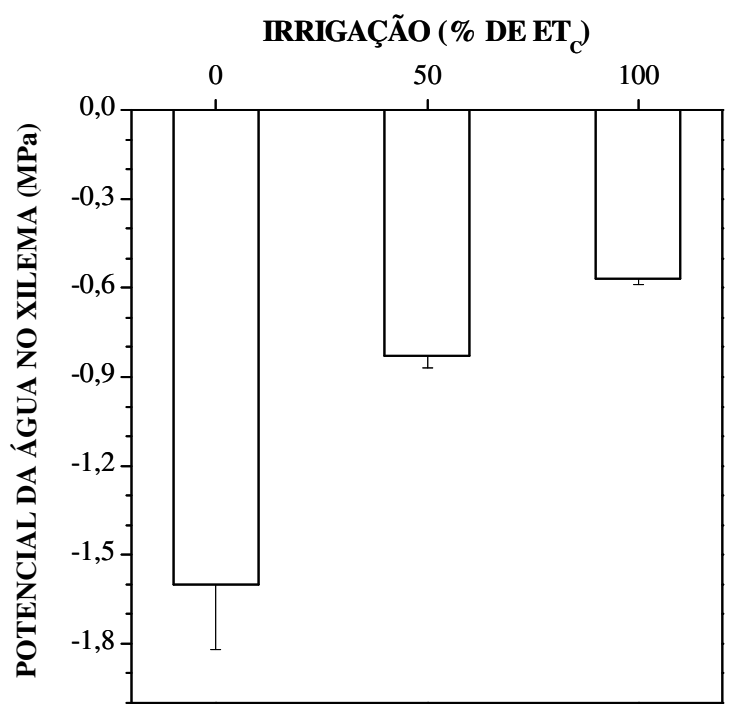

FIGURA 4. Potencial de água na planta, às 6 h, em limeira ácida 'Tahiti' submetida a 0; 50 e 100\% de reposição da água evapotranspirada pela cultura. Barras representam o valor médio de dez repetições e as linhas verticais, o erro-padrão da média.

Em geral, quando consideradas a assimilação de $\mathrm{CO}_{2}$ e a condutância estomática no decorrer do dia, houve tendência de aumento nas diferenças entre os tratamentos à medida que a demanda atmosférica aumentou. As plantas submetidas ao tratamento T1, em relação a T3, apresentaram decréscimos na assimilação de $\mathrm{CO}_{2}$ de $38 ; 50$ e $65 \%$ às $9 ; 12$ e 15 h, respectivamente. Esses resultados 
estão de acordo com SYVERTSEN \& LLOYD (1994) e MEDINA et al. (1998, 1999), que relatam a queda mais acentuada da fotossíntese de citros em condições de deficiência hídrica, em horários de maior temperatura e déficit de pressão de vapor do ar.

Em relação a T1, os resultados indicam que o suprimento de 50 (T2) e 100\% (T3) da necessidade hídrica da cultura proporcionou aumentos respectivos de 81 e 23\% (Tabela 1) na produção de limeiras ácidas 'Tahiti' com dois anos de idade. Tal fato sugere que o acréscimo de carbono assimilado (Figura 3) nos tratamentos irrigados foi utilizado no crescimento vegetativo (área foliar), influenciando a produção das plantas irrigadas. Assim, desde que a água afeta todas as fases do desenvolvimento dos frutos (ALBRIGO, 1992), a irrigação é uma prática que exerce grande influência sobre o desenvolvimento e produção dos citros.

\section{CONCLUSÕES}

A reposição de $100 \%$ da água evapotranspirada resultou em melhor desenvolvimento vegetativo e reprodutivo de plantas jovens de limeira acida 'Tahiti', em condições de campo.

\section{AGRADECIMENTOS}

Os autores agradecem à Fundação de Amparo à Pesquisa do Estado São Paulo - FAPESP, pelo suporte financeiro e ao Grupo de práticas em Irrigação e Drenagem - GPID/ESALQ/USP, pelo apoio e dedicação na coleta dos dados.

\section{REFERÊNCIAS}

ALLEN, R.G.; PEREIRA, L.S.; RAES D.; SMITH, M. Crop evapotranspiration: guidelines for computing crop water requirements. Rome: FAO, 1998. 300 p. (Irrigation and Drainage Paper, 56)

ALBRIGO, G. Influências ambientais no desenvolvimento de frutos cítricos. In: SEMINÁRIO INTERNACIONAL DE CITROS, 2., 1992, Bebedouro. Anais... Campinas: Fundação Cargill, 1992. p.100-6.

CAMPECHE, L.F.S. Construção, calibração e análise de funcionamento de lisímetros de pesagem para a determinação da evapotranspiração da cultura da lima ácida 'Tahiti' (Citrus latifolia Tan.). 2002. 62 f. Tese (Doutorado em Irrigação e Drenagem) - Escola Superior de Agricultura "Luiz de Queiroz", Universidade de São Paulo, Piracicaba, 2002.

CASTEL, J.R. Response of young Clementine citrus trees to drip irrigation. Acta Horticulturae, Leuven, n.335, p.313-24, 1993. Disponível em: <http://www.actahort.org/books/335/335_38.htm>. Acesso em: 16 maio 2005.

CASTEL, J.R. Response of young Clementine citrus trees to drip irrigation. I. Irrigation amount and number of drippers. Journal of Horticultural Science, Kent, v.69, n.3, p.481-9, 1994.

CASTEL, J.R.; BUJ, A. Growth and evapotranspiration of young, drip-irrigated Clementine trees. Proceedings of the International Society of Citriculture, Acireale, v.2, n.1, p.651-6, 1992.

DAVIES, F.S.; ALBRIGO, L.G. Citrus. Wallingford: CAB International, 1994. 254 p.

DAVIES F.S.; ZALMAN, G.R. Irrigation scheduling and growth of young 'Hamilin' orange trees. Proceedings of the Florida State Horticultural Society, Washington, v.113, n.1, p.53-7, 2000.

EMPRESA BRASILEIRA DE PESQUISA AGROPECUÁRIA. Centro Nacional de Pesquisa de Solos. Sistema Brasileiro de Classificação de Solos. Rio de Janeiro, 1999. 412 p.

GAYET, J.P.; BLEINROTH, E.W.; MATALLO, M.; GARCIA, E.E.C.; GARCIA, A.E.; ARDITO, E. F.G.; BORDIN, M.R. Lima ácida 'Tahiti'para exportação: procedimentos de colheita e pós-colheita. Brasília: Empresa Brasileira de Pesquisa Agropecuária, 1995. 36 p. (FRUPEX, 12). 
KAUFMANN, M. Evaluation of the pressure chamber method for measurement of water stress in citrus. Proceedings of the American Society for Horticultural Science, Alexandria, v.93, n.1, p.186-98, 1968.

LEVY, Y.; BIELORAI, H.; SHALHEVET, J. Long-term effects of different irrigation regimes on grapefruit tree development and yield. Journal of the American Society for Horticultural Science, Alexandria, v.103, n.5, p.680-3, 1978.

MACHADO, E.C.; MEDINA, C.L.; GOMES, M.M.A. Teor de água no substrato de crescimento e fotossíntese em laranjeira 'Valência'. Bragantia, Campinas, v.58, n.2, p.217-26, 1999.

MARLER, T.E.; DAVIES, F. Microsprinkler irrigation and growth of young 'Hamilin' orange trees. Journal of the American Society for Horticultural Science, Alexandria, v.115, n.1, p.45-51, 1990.

MARCONDES, P.T.S. Manejo do florescimento e da produção da lima ácida 'Tahiti' com reguladores de crescimento e derriça. 1991. 120 f. Dissertação (Mestrado em Fruticultura Tropical) Escola de Agronomia, Universidade Federal da Bahia, Cruz das Almas, 1991.

MEDINA, C.L.; MACHADO, E.C.; PINTO, J.M. Fotossíntese de laranjeira 'Valência' enxertada sobre quatro porta-enxertos e submetida à deficiência hídrica. Bragantia, Campinas, v.57, n.1, p.1-14, 1998.

MEDINA, C.L.; MACHADO, E.C.; GOMES, M.M.A. Condutância estomática, transpiração e fotossíntese em laranjeira 'Valência' sob deficiência hídrica. Revista Brasileira de Fisiologia Vegetal, Londrina, v.11 n.1, p.29-34, 1999.

NOBEL, P.S. Physicochemical and environmental plant physiology. San Diego: Academic Press, 1999. $473 \mathrm{p}$.

PASSOS, O.S.; COELHO, Y.S.; CUNHA SOBRINHO, A.P. Variedades de copa e porta-enxertos de citros. In: ENCONTRO NACIONAL DE CITRICULURA, 4., 1977, Aracaju. Anais... Aracaju: Sociedade Brasileira de Fruticultura, 1977. p.21-41.

PEREIRA, A.R.; ANGELOCCI, L.R.; SENTELHAS, P.C. Agrometeorologia: fundamentos e aplicações práticas. Guaíba: Agropecuária, 2002. 478 p.

SENTELHAS, P.C.; PEREIRA, A.R. A maior estiagem do século? Notícias Piracena, Piracicaba, v.6, n.50, p.1, 2000.

SHALHEVET, J.; LEVY, Y. Citrus trees. In: STEWART, B.A.; NIELSEN, D.R. (Ed.). Irrigation of agricultural crops. Madison: American Society of Agronomy, 1990. p.951-86.

SYVERTSEN, J.P. Minimum leaf water potential and stomatal closure in citrus leaves of different ages. Annals of Botany, London, v.49, n.6, p.827-34, 1982.

SYVERTSEN, J.P.; LLOYD, J.J. Citrus. In: SCHAFFER, B.; ANDERSON, P.C. (Ed.). Handbook of environmental physiology of fruit crops: sub-tropical and tropical crops. Boca Raton: CRC Press, 1994. v.2, p.65-99.

RAIJ, B. Van; SILVA, N.M.; BATAGLIA, O.C.; QUAGGIO, J.A.; HIROCE, R.; CANTARELLA, H.; BELLINAZZI, J.R.; DECHEN, A.R.; TRANI, P.E. Recomendações de adubação e calagem para o Estado de São Paulo. Campinas: Instituto Agronômico, 1992. 107 p. (Boletim Técnico, 100)

VU, J.C.V.; YELENOSKY, G. Water deficit and associated changes in some photosynthetic parameters in leaves of 'Valencia' orange (Citrus sinensis [L.] Osbeck). Plant Physiology, Rockville, v.88, n.2, p.375-8, 1988.

WELLES, J.M.; COHEN, S. Canopy structure measurement by gap fraction analysis using commercial instrumentation. Journal of Experimental Botany, Oxford, v.47, n.302, p.1335-42, 1996. 